\title{
Suppression of Spermatogenesis in Man Induced by Nal- Glu Gonadotropin Releasing Hormone Antagonist and Testosterone Enanthate (TE) Is Maintained by TE Alone*
}

\author{
R. S. SWERDLOFF, C. J. BAGATELL, C. WANG, B. D. ANAWALT, N. BERMAN, \\ B. STEINER, AND W. J. BREMNER
}

\begin{abstract}
Division of Endocrinology, Departments of Medicine and Pediatrics, Harbor-University of California Los Angeles Medical Center (R.S.S., C.W., N.B., B.S.), Torrance, California 90509; and Division of Endocrinology, Department of Medicine, Veterans Administration Puget Sound Health Care System (C.J.B., B.D.A., W.J.B.), Seattle, Washington 98108
\end{abstract}

\begin{abstract}
GnRH antagonists plus testosterone (T) suppress LH and FSH levels and inhibit spermatogenesis to azoospermia or severe oligozoospermia. High-dose $\mathrm{T}$ treatment alone has been shown to be an effective male contraceptive (contraceptive efficacy rate of 1.4 per 100 person yr). Combined $\mathrm{GnRH}$ antagonist and $\mathrm{T}$ induces azoospermia more rapidly and at a higher incidence than $\mathrm{T}$ alone; this combination has therefore been proposed as a prototype male contraceptive. However, because $\mathrm{GnRH}$ antagonists are expensive to synthesize and difficult to deliver, it would be desirable to rapidly suppress sperm counts to low levels with GnRH antagonist plus $\mathrm{T}$ and maintain azoospermia or severe oligozoospermia with $\mathrm{T}$ alone. In this study, 15 healthy men (age 21-41 yr) with normal semen analyses were treated with T enanthate (TE) $100 \mathrm{mg}$ im/week plus $10 \mathrm{mg}$ Nal-Glu GnRH antagonist sc daily for 12 weeks to induce azoospermia or severe oligozoospermia. At 12-16 weeks, 10 of 15 subjects had zero sperm counts, and 14 of 15 had sperm counts less than $3 \times 10^{6} / \mathrm{mL}$. The 14 who were suppressed on combined treatment were maintained on TE
\end{abstract}

alone $(100 \mathrm{mg} /$ week $\mathrm{im})$ for an additional 20 weeks. Thirteen of 14 subjects in the TE alone phase had sperm counts maintained at less than $3 \times 10^{6} / \mathrm{mL}$ for 20 weeks. Ten remained persistently azoospermic or had sperm concentration of $0.1 \times 10^{6} / \mathrm{mL}$ once during maintenance. Mean LH and FSH levels in the subjects were suppressed to $0.4 \pm 0.2$ $\mathrm{IU} / \mathrm{L}$ and $0.5 \pm 0.2 \mathrm{IU} / \mathrm{L}$ in the induction phase, which was maintained in the maintenance phase. The 1 subject who failed to suppress sperm counts during induction had serum LH and FSH reduced to 0.3 and $0.5 \mathrm{IU} / \mathrm{L}$, respectively. The subject who failed to maintenance had LH and FSH suppressed to 1.0 and $0.2 \mathrm{IU} / \mathrm{L}$, respectively, during the induction phase but these rose to 1.6 and $2.1 \mathrm{IU} / \mathrm{L}$, respectively, during maintenance. Failure to suppress or maintain low sperm counts may be related to incomplete suppression of serum LH and FSH levels. We conclude that sperm counts suppressed with GnRH antagonist plus $\mathrm{T}$ can be maintained with relatively low dose TE treatment alone. This concept should be explored further in the development of effective, safe, and affordable hormonal male contraceptives. (J Clin Endocrinol Metab 83: 3527-3533, 1998)

$\mathrm{I}^{\mathrm{N}}$ recently completed multicenter clinical trials in over 600 couples, hormonal suppression of spermatogenesis by testosterone enanthate (TE) ( $200 \mathrm{mg} /$ week im) was shown to achieve severe oligozoospermia in $97.8 \%$ of male volunteers $(1,2)$. This suppression of spermatogenesis is maintained for the duration of testosterone $(\mathrm{T})$ administration. Return of sperm production was a rare occurrence during the continuation of hormonal treatment. More importantly, the attainment of severe oligozoospermia $\left(<3 \times 10^{6} / \mathrm{mL}\right)$ and

Received April 27, 1998. Revision received June 25, 1998. Accepted July 6, 1998.

Address all correspondence and requests for reprints to: R. S. Swerdloff, Division of Endocrinology, Harbor-University of California Los Angeles Medical Center, 1000 West Carson Street, Torrance, California 90509. E-mail: Swerdloff@gcrc.humc.edu.

* Support for this project (CSA 94-145 and CSA 94-146) was provided by the Contraceptive Research and Development (CONRAD) Program, Eastern Virginia Medical School under a Cooperative Agreement (CCP-A-00-92-00015-15) with the United Agency for International Development (USAID). The views expressed by the authors do not necessarily reflect the views of USAID or CONRAD. Presented in part at the 79th Annual Meeting of The Endocrine Society, Minneapolis, Minnesota, June 1997. Supported by CONRAD Program (CSA 94-146 and CSA 94-145), NIH Grant M01 RR00425 to the General Clinical Research Center at Harbor-University of California Los Angeles Medical Center Medical Center, and NIH Grant P50HD12629 to the Population Center, University of Washington.

azoospermia in these men was associated with high contraceptive efficacy. The overall pregnancy (contraceptive efficacy) rate was 1.4 per 100 person yr (95\% confidence interval, $0.4-3.7$ ). This efficacy rate was equivalent or better than reversible hormonal methods currently used by women such as the oral pills, injectables, or implants. The prototype hormonal contraception used in these multicenter studies was administration of TE $200 \mathrm{mg}$ im once per week. This resulted in serum levels in the supraphysiological or upper normal range, even when $\mathrm{T}$ levels were measured during the expected trough. Acceptable but noticeable reported side effects included weight gain, increased oiliness of the skin, and development of acne $(1,2)$. A lower dose of TE, e.g. 100 $\mathrm{mg}$ /week had been shown to induce azoospermia or severe oligozoospermia in only $50-70 \%$ of non-Asian men (3-8) but resulted in azoospermia in 100\% of Asian men (9).

GnRH antagonists, when administered to man, inhibited gonadotropin secretion rapidly and without the initial stimulation of gonadotropins observed with the GnRH agonists. GnRH antagonists were shown to profoundly suppress serum FSH and T levels and to inhibit spermatogenesis, resulting in azoospermia or severe oligozoospermia in over $90 \%$ of men studied (10-22). Because $\mathrm{T}$ levels were suppressed, various replacement doses of T (TE 25-200 mg/ week im) were used $(13,16,19,23)$. Though effective, GnRH 
antagonists were expensive to synthesize, had to be administered daily by SC injections, and produced local skin irritation in most of the subjects.

The present study was designed to test the hypothesis that when suppression of spermatogenesis to severe oligo- or azoospermia was induced by the combined administration of GnRH antagonist and T, this suppression would be maintained by $\mathrm{T}$ administration in a dose inadequate to induce maximal suppression of spermatogenesis if used alone. In previous studies, TE $100 \mathrm{mg}$ / week im administered alone for 6 months resulted in azoospermia in only 33\% and severe oligozoospermia in $61 \%$ of normal volunteers in the United States (mainly Caucasians) (24). This dose of TE, previously shown to reverse symptoms of hypogonadism in androgendeficient men, was chosen to be the replacement dose for the induction of suppression of spermatogenesis with the regimen GnRH antagonist plus T, and subsequently as a single agent during the maintenance phase of the study. If this hypothesis is proven to be true, then other combination regimens such as a nonpeptide GnRH antagonist or a progestagen plus $\mathrm{T}$ (24) could also rapidly induce severe spermatogenic suppression that would be maintained by a lower, more physiological dose of T. Such a combination might be a practical and more effective method of male contraception.

\section{Subjects and Methods}

\section{Subjects}

Fifteen healthy male volunteers between 21-41 yr of age were recruited from the community via radio and newspaper advertisements. They were studied either at the Harbor-UCLA Medical Center $(n=8)$ or the VA Puget Sound Health Care System $(n=7)$. Twelve of the subjects were non-Hispanic whites, two were Hispanics, and one was East Asian. The subjects were in good health as determined by medical history, physical examination, and screening laboratory tests including blood counts, renal and liver function tests, serum lipid panel, and serum $\mathrm{T}, \mathrm{FSH}$, and LH levels. All subjects had normal semen analyses as defined by the $\mathrm{WHO}$ guidelines (25) i.e. semen volume over $2.0 \mathrm{~mL}$, sperm concentration over $20 \times 10^{6} / \mathrm{mL}$, motility over $50 \%$ (includes all motile spermatozoa) and normal morphology over $20 \%$ by strict criteria. (The percent normal morphology threshold was set at $20 \%$ based on data generated in our laboratory from semen analyses of 61 normal, healthy volunteers). All subjects were within plus or minus $20 \%$ of ideal body weight. Other methods of contraception were used by the subjects or their partners throughout the study period. All subjects signed an informed consent form, and the study was approved by the Institution Review Board of each institution.

\section{Study design}

The study was divided into four phases (Fig. 1): pretreatment phase of a minimum of 6 weeks duration, induction phase of 12 weeks, maintenance phase of 20 weeks, and posttreatment phase of a minimum of 12 weeks. During the pretreatment phase at least four semen samples were obtained from each volunteer, and a skin test for GnRH antagonist was performed. Skin tests were performed with intradermal injection of $10 \mu \mathrm{g} \mathrm{GnRH}$ antagonist. Only volunteers with a wheal of equal to or less than $0.5 \mathrm{~cm}$ with no pseudopods were admitted to the study. During the induction phase, the volunteers administered Nal-Glu GnRH antagonist $10 \mathrm{mg}$ sc daily by self-administration and TE $100 \mathrm{mg}$ im weekly by the study coordinators. On occasions when the volunteers could not return to the clinic, TE injections were administered by the volunteers after careful instructions from the medical staff. At the end of 12 weeks, volunteers who had attained azoospermia or a sperm concentration equal to or less than $3 \times 10^{6} / \mathrm{mL}$ on two consecutive semen analyses entered into a 20-week maintenance period during which they received TE $100 \mathrm{mg} /$ week im alone. If at the end of the induction period the

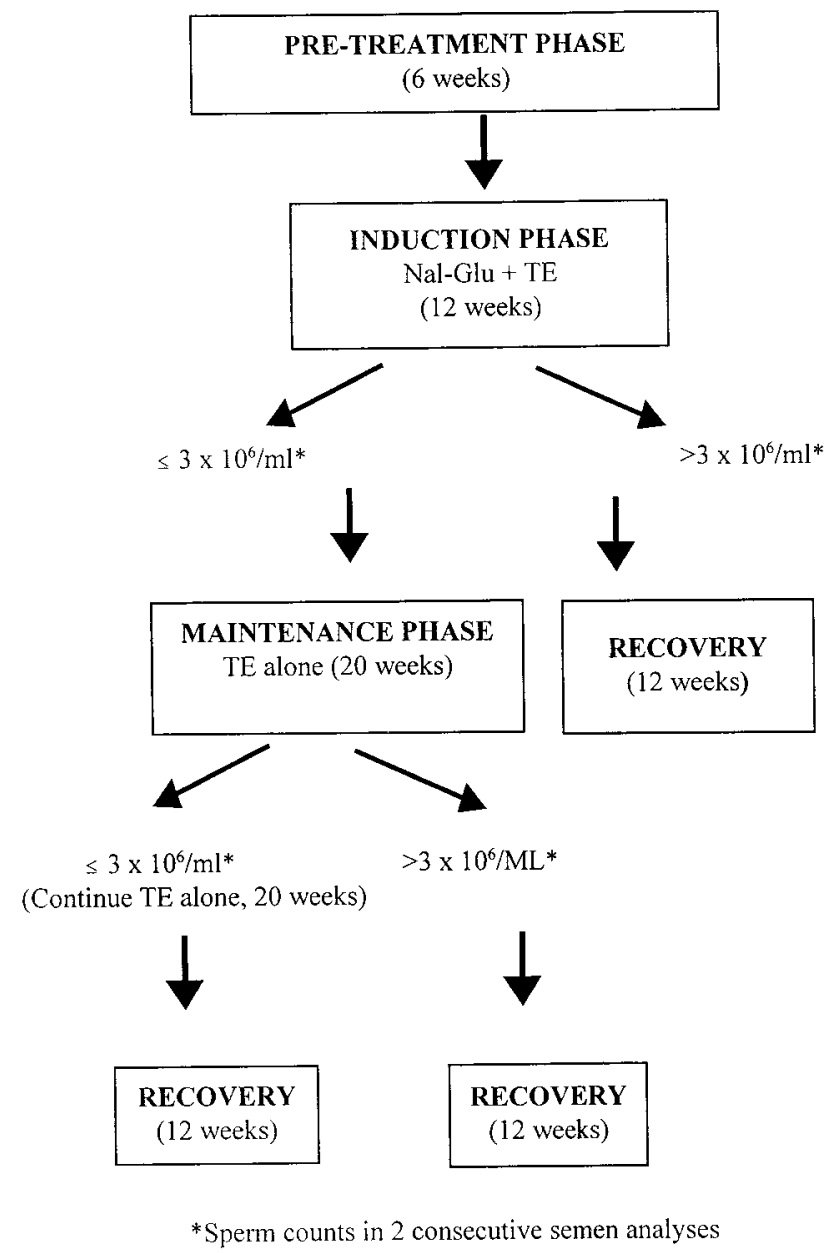

FIG. 1. Outline of study design.

volunteer did not suppress to severe oligozoospermia (defined as sperm count $\leq 3 \times 10^{6} / \mathrm{mL}$ ) or azoospermia on two consecutive semen analyses, he entered recovery phase. During the entire maintenance phase, TE im injections $100 \mathrm{mg} /$ week were administered for another 20 weeks. Volunteers were discontinued from the maintenance period and entered into recovery phase if sperm concentrations reached more than $3 \times$ $10^{6} / \mathrm{mL}$ in two consecutive semen samples at any time. The recovery phase lasted for a minimum of 12 weeks or until two consecutive semen analyses showed sperm concentration of over $20 \times 10^{6} / \mathrm{mL}$. Semen samples were collected at 2-week intervals throughout the study. Blood samples for hormones were collected at 2-week intervals before and during the induction phase and then at 4-week intervals during treatment and recovery phase. Complete blood counts, clinical chemistry, and lipid panel were done during and at the end of induction, maintenance, and recovery phases. In addition, psychosexual diary data for 7 consecutive days were collected by volunteers at monthly intervals throughout the study period $(26,27)$.

\section{Study medications}

The Nal-Glu GnRH antagonist was obtained from J. Rivier, Ph.D. (Salk Institute, La Jolla, CA) and was made available through the Contraceptive Development Branch, Center for Population Research, National Institute of Child Health and Human Development. Nal-Glu antagonist was supplied as a lyophilized powder that was dissolved in bacteriostatic water containing $4 \mathrm{~g} / \mathrm{L}$ mannitol and then diluted to a concentration of $10 \mathrm{mg} / \mathrm{mL}$. The preparation was passed through a $0.2-\mu \mathrm{m}$ filter into sterile vials under sterile conditions by the research pharmacist at the Harbor-UCLA Medical Center. Each batch of vials was tested for pyrogenicity and sterility before use. Volunteers self-admin- 
istered Nal-Glu GnRH antagonist sc in the abdominal area each day. The volunteers were asked to record the local reaction caused by the GnRH antagonist. TE was a gift from BioTechnology General (Iselin, NJ) in 5 -mL vials of $200 \mathrm{mg} \mathrm{TE} / \mathrm{mL}$ sesame oil. TE was administered to the volunteers by the nurse coordinator, or volunteers were taught how to self-administer the injections.

\section{Methods}

Serum FSH and LH were measured by highly sensitive and specific immunofluorometric assays with reagents provided by Delfia (Wallac, Inc., Gaithersburg, MD) (16). The sensitivities of these assays was 0.1 $\mathrm{IU} / \mathrm{L}$, and lower limit of quantitation was $0.2 \mathrm{IU} / \mathrm{L}$ for both LH and FSH. The intra- and interassay coefficients of variation were 4.3 and $11.0 \%$, respectively, for serum LH and 5.2 and $12.0 \%$, respectively, for serum FSH. Adult normal range for serum LH was $0.7-6.0 \mathrm{IU} / \mathrm{L}$, and FSH was 0.5-7 IU/L. Serum T was measured by RIA after an extraction procedure with hexane and ethyl-acetate. The reagents for the RIA were obtained from ICN Pharmaceuticals, Inc. (Costa Mesa, CA). The lower limit of quantitation of serum $\mathrm{T}$ in the assay was $0.87 \mathrm{nmol} / \mathrm{L}(25 \mathrm{ng} / \mathrm{dL})$ and the intra- and interassay coefficients of variation were 7.3 and 11.1, respectively, for the adult male range, which in our laboratory was 10.1-36.1 nmol/L (290-1042 ng/dL) (28). All samples from each subject were measured in the same assay. Complete blood counts, clinical chemistry, and lipid panels were measured by the hospital laboratory of each center. Semen analyses (semen volume, sperm concentration, and total sperm concentration) were performed according to the methods described in the WHO Laboratory Manual for Semen Analyses and SpermCervical Mucus Interaction (25).

\section{Statistical analyses}

Descriptive statistics were calculated for each variable at each time point. Continuous variables were transformed, if necessary, to meet the requirements of ANOVA. Outcome variables including sperm concentration, serum hormone levels, clinical biochemistry, and scores from psychosexual diaries were analyzed using repeated measured ANOVA. Time in treatment (including baseline values obtained during the pretreatment period) was used as the repeated (within subject factor). Post test contrasts were used to compare subsequent values to baseline.

There was no significant difference in the baseline or response to treatment in any of the outcome variables between the two centers. The results, expressed as mean \pm SEM, represented data from both centers.

\section{Results}

\section{Suppression of spermatogenesis}

The combination of Nal-Glu GnRH antagonist (10 ng/day sc) and TE (100 mg/week im) induced a rapid and progressive suppression of sperm concentration in all subjects during the induction phase (Fig. 2). The mean sperm concentration of all subjects was suppressed to a very low level during the maintenance phase with TE alone in all subjects. Upon withdrawal of TE injections, sperm concentrations rose gradually, and by 12 weeks all subjects reached their pretreatment levels. The semen volume was not significantly changed during the study, and total sperm count paralleled the decrease in the sperm concentration (defined as semen volume $\times$ sperm concentration $\times 10^{6}$ per ejaculate).

The proportion of subjects who reached azoospermia or severe oligozoospermia (as defined as $<3$ million $/ \mathrm{mL}$ ) is shown in Fig. 3. By 10 weeks of the induction phase, 10 of the 15 subjects suppressed to azoospermia and another 4 to severe oligozoospermia. In only 1 (subject 122) did the sperm concentration fail to suppress to severe oligozoospermia. This subject had wheals at the injection sites that lasted for 2 weeks after each injection. His serum FSH and LH failed to suppress to nondetectable levels. He entered recovery
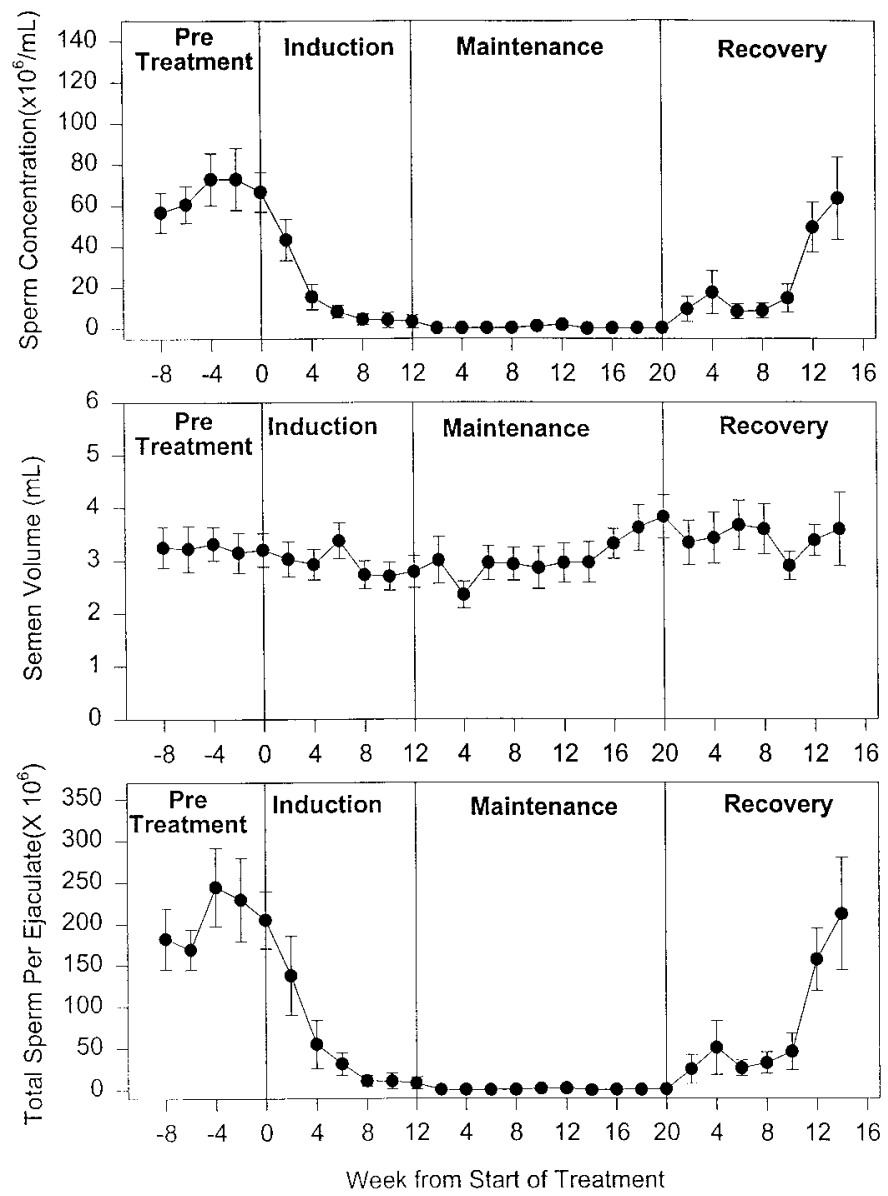

FIG. 2. Sperm concentration (upper panel), semen volume (middle panel), and total sperm count per ejaculate (lower panel) during pretreatment, induction (Nal-Glu GnRH antagonist plus TE), maintenance (TE alone), and recovery phases. Data represent mean \pm SEM. Numbers of subjects who provided samples for analyses at each week of study are given at bottom of each panel.

without going through the maintenance phase. During the maintenance phase of 20 weeks, 12 out of 14 subjects reached azoospermia, which was persistent in 8 subjects. Two subjects each had a sperm concentration of $0.1 \times 10^{6} / \mathrm{mL}$ once during the 20 weeks of maintenance. Another 2 out of the 14 subjects remained persistently severely oligozoospermic with sperm concentrations less than $3 \times 10^{6} / \mathrm{mL}$. Thus $13 / 14$ subjects $(93 \%)$ remained suppressed to severe oligozoo- or azoospermia throughout the 20-week maintenance phase with TE alone. A single (subject 105) escaped suppression while on TE maintenance alone. His sperm concentration was $0.03 \times 10^{6} / \mathrm{mL}$ at the end of induction and reached azoospermia at week 2 of maintenance, but by week 8 it rose to $1.6 \times 10^{6} / \mathrm{mL}$. At weeks 10 and 12 his sperm concentration rose to 11.8 and $22.3 \times 10^{6} / \mathrm{mL}$, respectively. He entered the recovery phase at this time point.

\section{Serum LH, FSH, and T levels}

Serum LH and FSH levels (Fig. 4) showed a dramatic decrease with GnRH antagonist plus TE treatment. Mean serum LH and FSH levels were suppressed to $0.4 \pm 0.2 \mathrm{IU} / \mathrm{L}$ and $0.5 \pm 0.2 \mathrm{IU} / \mathrm{L}$, respectively $(P<0.0001$ when compared 
Fig. 3. Percent of subjects whose sperm count was suppressed to azoospermia (open section of bar), severe oligozoospermia $\left(<3 \times 10^{6} / \mathrm{mL}\right)$ (gray section of bar) during different phases of study.

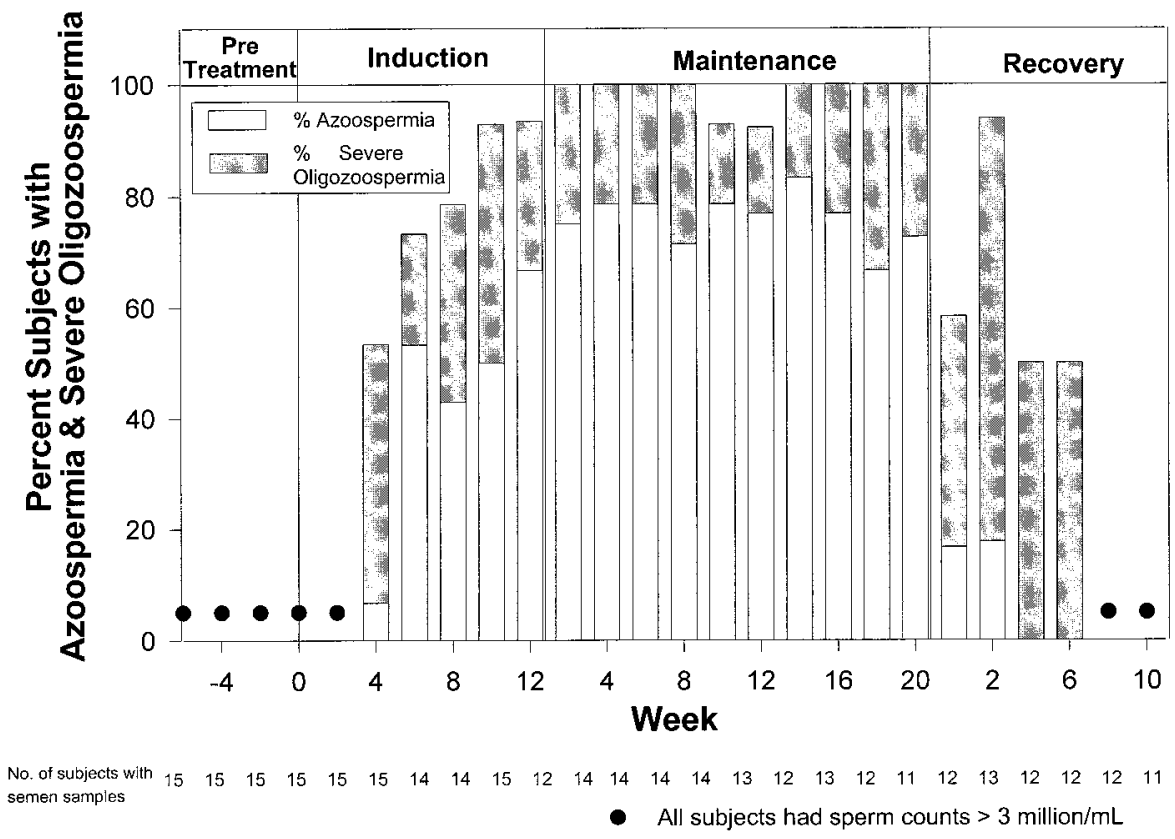

Discussion

with pretreatment levels for both hormones), by week 4 of induction and remained suppressed throughout the induction and maintenance periods. In subject 122 , whose sperm concentration failed to decrease below $3 \times 10^{6} / \mathrm{mL}$ during induction, serum LH and FSH levels were 0.3 and $0.5 \mathrm{IU} / \mathrm{L}$, respectively, at week 12 of $\mathrm{GnRH}$ antagonist plus TE treatment. In subject 105 who escaped during maintenance, serum LH and FSH levels were 1.0 and $0.2 \mathrm{IU} / \mathrm{L}$, respectively, at the end of induction. Both levels gradually rose, and by the time his sperm concentration at week 10 was above $3 \times$ $10^{6} / \mathrm{mL}$, his serum gonadotropins were 1.6 IU / L for LH and 2.1 IU / L for FSH. Mean serum T concentration for the group was $15.0 \pm 0.9 \mathrm{nmol} / \mathrm{L}$ at baseline (week 0 ) and remained within the normal range in all subjects throughout induction, treatment, and recovery phases (Fig. 4).

\section{Psychosexual function}

As shown in Fig. 5, sexual motivation (including average scores of sexual desire, sexual dreams, anticipation of sex, and flirting) and sexual performance (including average scores of intercourse, masturbation, orgasm, ejaculation, and erection) remained unchanged throughout the study. Positive and negative mood summary scores also remained unchanged throughout the treatment and recovery phase.

\section{Adverse effects}

In all subjects, Nal-Glu GnRH antagonist administered sc in the abdominal area caused local irritation. The redness and itchiness lasted for 2-3 days, but in some subjects the wheal lasted up to 2 weeks. Despite the presence of local irritation, none of the 15 subjects withdrew from the study for this reason. There was no untoward effect reported with the TE injections. Complete blood counts, clinical chemistry, total cholesterol, high-density lipoprotein cholesterol, low-density lipoprotein cholesterol, and triglycerides were not significantly changed throughout the treatment period.
Previous studies have demonstrated that suppression of gonadotropins (LH and FSH) by various hormonal regimens reversibly inhibits spermatogenesis and markedly lowers sperm counts $(7,8)$. Although $\mathrm{T}$ alone is an effective suppressor of spermatogenesis, combination regimens such as $\mathrm{GnRH}$ antagonists or progestagens plus $\mathrm{T}$ are more rapid in onset and more efficient in lowering sperm counts to or near zero $(7,8,29)$. Our data from the induction phase of the present study showed that GnRH antagonist plus TE was highly effective in suppression of spermatogenesis in normal male volunteers. These results confirmed the previous studies of our group and others $(13,16,18)$. Similar to previous data, only 1 out of $15(6.7 \%)$ subjects failed to suppress to severe oligozoospermia or azoospermia. We previously demonstrated that this suppression of spermatogenesis by GnRH antagonists most likely occurred by enhanced apoptosis of germ cells (30).

We also demonstrated that when severe oligozoo- or azoospermia was achieved by hormonal treatment, this level of suppression of human spermatogenesis could be maintained by T alone. Serum FSH and LH levels showed that the only subject who failed suppression and the subject who had rebound of sperm counts during maintenance had gonadotropin levels above the lower limit detectability even at the end of induction. Failure to suppress or maintain severe oligozoospermia appeared to be related to the degree of suppression of both gonadotropins. Previous studies demonstrated that this dose of TE administered to normal men alone would suppress spermatogenesis to azoospermia in about $50 \%$ and to severe oligozoospermia in about $75 \%$ of non-Asian men. Thus, we showed for the first time that if gonadotropin secretion and spermatogenesis were severely suppressed, absent or very low sperm counts could be sustained with a dose of TE that on its own was suboptimal in achieving a similar degree of inhibition of spermatogenesis. 


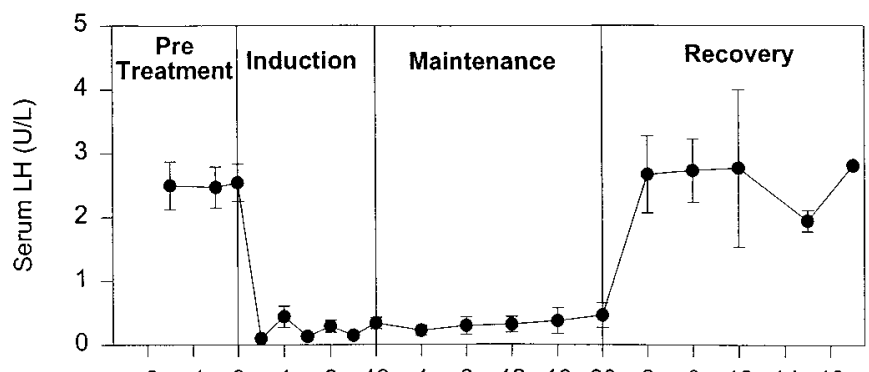

$\begin{array}{llllllllllllllll}-8 & -4 & 0 & 4 & 8 & 12 & 4 & 8 & 12 & 16 & 20 & 2 & 6 & 10 & 14 & 18\end{array}$
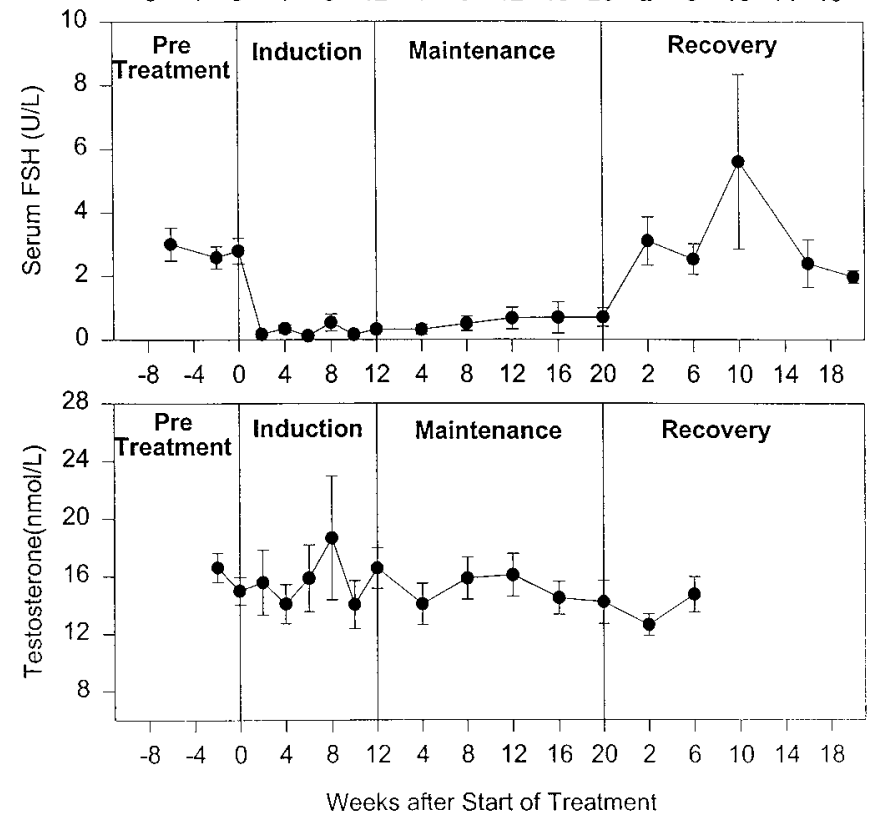

FIG. 4. Serum LH (upper panel), FSH (middle panel), and T (lower panel) levels (mean \pm SEM) during induction, maintenance, and recovery phases of study. Normal adult male range was 1.0-8.1 IU/L for LH, 1.0-6.9 IU/L for FSH, and (10.1-36.1) nmol/L for T.

In this study, the maintenance period with androgens alone was continued for 20 weeks. Although longer maintenance data are not yet available, it is logical to assume that spermatogenesis should remain suppressed as long as the gonadotropin secretion remains inhibited. The GnRH antagonist used in the present study frequently produced local skin irritability at the injection site. It is likely that if spermatogenesis were inhibited by low dose $\mathrm{T}$ (e.g. $100 \mathrm{mg} /$ week im) plus a nonpeptide GnRH antagonist without local side effects, then low dose TE given alone would maintain suppression with fewer side effects than the supraphysiological dose of TE $(200 \mathrm{mg} /$ week im) used in prior studies $(1,2)$. Moreover, it is likely that other hormonal regimens, such as progestagens plus androgens or high dose androgens alone could induce marked inhibition of sperm production, which could be maintained by lower doses of the steroid hormone combinations or androgens alone.

In the non-human primate, Weinbauer et al. (31) administered GnRH antagonist (Cetrorelix, Asta Medica, Frankfurt am Main, Germany) daily for 18 weeks with or without $\mathrm{T}$ replacement ( $\mathrm{T}$ buciclate $200 \mathrm{mg}$ /animal). The results were compared with a third group who received cetrorelix for 7 weeks followed by $\mathrm{T}$ buciclate maintenance for 12 weeks. The azoospermia induced by the GnRH antagonist was not main-
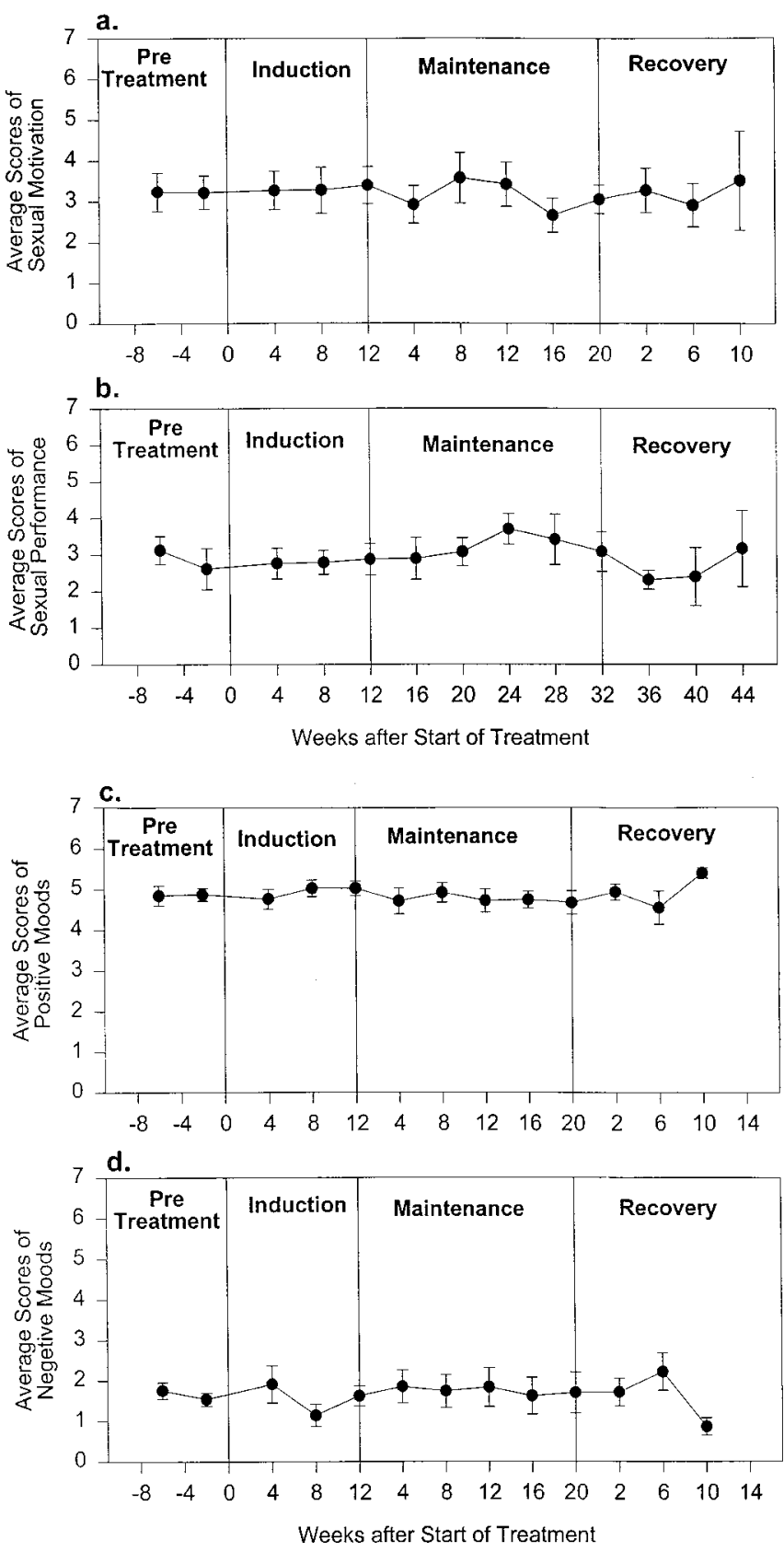

FIG. 5. Average scores of sexual motivation (desire, dreams, anticipation, flirting) (a), sexual performance (intercourse, masturbation, orgasm, ejaculation, and erections) (b), positive mood (alert, energetic, friendly, well) (c), and negative mood (angry, irritable, sad, tired, nervous) (d) at pretreatment, induction, maintenance, and recovery phases.

tained when $\mathrm{T}$ buciclate was administered. During the reappearance of germ cells in the ejaculate, serum LH levels were suppressed, whereas serum inhibin levels rose, suggesting FSH escape.

The previous reported study of Behre et al. (32) used an induction regimen with GnRH antagonist (cetrorelix $10 \mathrm{mg}$ / day sc for 5 days, then $2 \mathrm{mg} /$ day for 12 weeks) plus 19 nor-T (19 NT) im (400 mg 19 NT followed by $200 \mathrm{mg} 19$ NT once every 3 weeks for 26 weeks) to induce severe suppression of 
spermatogenesis in all 6 normal male volunteers within 12 weeks. When the GnRH antagonist was withdrawn after 12 weeks, rebound of gonadotropins occurred, and significant amounts of spermatozoa reappeared in the ejaculate in 5 out of 6 subjects despite the continuation of 19 NT treatment. Their conclusion was that GnRH antagonist plus 19 NT led to azoospermia that could not be maintained by continued 19 NT injections. Their data were different from the current study in which only 1 out of 14 subjects escaped from gonadotropin suppression when GnRH antagonist treatment was withdrawn, and the subjects were continued on TE injections. The interval of 19 NT administration was 3 weeks, which could be insufficient to maintain the suppression of gonadotropins and spermatogenesis to very low levels observed during the androgen alone maintenance phase of the current study.

GnRH antagonist in the current formulation would not be a feasible agent for male contraceptive development because of its route of administration (daily sc), local skin irritation (wheals, itchiness, and discomfort), and high cost of production. Long-acting formulation of an GnRH antagonist as microsphere injections or gel implants might be developed. New nonpeptide GnRH analogs developed by molecular drug modeling methods would permit the development of orally active or long- acting products that might have the gonadotropin suppressive potency of the currently available $\mathrm{GnRH}$ antagonists but devoid of the local histamine-like effects. It should be noted that the dose of TE tested (100 $\mathrm{mg} /$ week im injections) produced no apparent adverse effects. The levels of serum $\mathrm{T}$ were unchanged from the observed pretreatment levels both during the induction as well as the maintenance phases. The serum $\mathrm{T}$ levels measured were obtained before the next injections, and higher serum $\mathrm{T}$ might be present during the first few days following each TE administration. However, this dose of TE did not induce similar side effects as reported with TE $200 \mathrm{mg} /$ week in the multicenter contraceptive efficacy study $(1,2)$. Furthermore, serum hemoglobin, hematocrit, and high-density lipoprotein cholesterol levels were not significantly altered, and normal sexual function was maintained during both induction and maintenance. New long-acting injectable T preparations such as TE buciclate $(33,34)$ and $\mathrm{T}$ microspheres $(35)$ or even $\mathrm{T}$ implants (36) might serve as acceptable maintenance regimens once almost complete suppression of spermatogenesis was attained by combination methods.

We conclude that this paradigm of complete gonadotropin suppression by GnRH antagonist or other gonadotropin suppressive agents followed by maintenance with a near physiological dose of $\mathrm{T}$ could be used in the development of new, long-acting, sustained release hormonal methods of male contraception.

\section{Acknowledgments}

We thank Tina Davidson, R.N., Elaine Rost, B.A., and the nurses of the GCRC at Harbor-UCLA Medical Center for conducting the study; J. Rivier, Ph.D. from the Salk Institute for the Nal-Glu GnRH antagonist; Laura Hull, B.A., for data management and graphic presentation; Stephanie Griffiths, M.Sc., Sima Baravarian, Ph.D., and Andrew Leung, H.T.C. for hormone measurements; and Sally Avancena, M.A., for preparation of the manuscript.

\section{References}

1. World Health Organization Task Force on Methods for the Regulation of Male Fertility. 1990 Contraceptive efficacy of testosterone-induced azoospermia in normal men. Lancet. 336:955-959.

2. World Health Organization Task Force on Methods for the Regulation of Male Fertility. 1996 Contraceptive efficacy of testosterone-induced azoospermia and oligozoospermia in normal men. Fertil Steril. 65:821-829.

3. Cunningham GR, Silverman VE, Kohler DO. 1978 Clinical evaluation of testosterone enanthate for induction and maintenance of reversible azoospermia in man. In: Patanelli DJ, ed. Hormonal control of male fertility. Bethesda, MD: Department of Health Education and Welfare. Publication (NIH) 78-1097; 71-92.

4. Swerdloff RS, Palacios A, McClure RD, Campfield LA, Brosman SA. 1978 Clinical evaluation of testosterone enanthate in the reversible suppression of spermatogenesis in the human male: efficacy, mechanism of action, and adverse effects. In: Patanelli DJ, ed. Hormonal control of male fertility. Bethesda, MD: DHEW Publication (NIH) 78-1097; 41-70.

5. Mauss J, Borsch G, Bormacher K, Richter E, Leyendecker G. 1978 Seminal fluid analyses, serum FSH, LH and testosterone in seven males before, during and after $250 \mathrm{mg}$ testosterone enanthate weekly over 21 weeks. In: Patanelli DJ, ed. Hormonal control of male fertility. Bethesda, MD: DHEW Publication (NIH) 78-1097; 93-122.

6. Paulsen CA, Bremner WJ, Leonard JM. 1982 Male contraception. In: Mishell DR, ed. Clinical trials in advances in fertility research. New York: Rowen Press; pp 157-170.

7. Cummings DE, Bremner WJ. 1994 Prospects for new hormonal male contraceptives. Endocrinol Metab Clin North Ama. 23:893-922.

8. Wang C, Swerdloff RS, Waites GMH. 1994 Male contraception: 1993 and beyond. In: Van Look PFA, Perez Palacio G, eds. Contraceptive research and development 1984 to 1994. New Delhi: Oxford University Press; 121-134.

9. Arsyad KM. 1993 Sperm function in Indonesian men. Int J Androl. 16:355-361.

10. Pavlou SN, Debold CR, Island DP, et al. 1986 Single subcutaneous doses of a luteinizing hormone-releasing hormone antagonist suppress serum gonadotropin and testosterone levels in normal men. J Clin Endocrinol Metab. 63:303-308.

11. Pavlou SN, Wakefield GB, Island DP, et al. 1987 Suppression of pituitarygonadal function by a potent new luteinizing hormone-releasing hormone antagonist in normal men. J Clin Endocrinol Metab. 64:931-936.

12. Pavlou SN, Wakefield G, Schlechter NL, et al. 1989 Mode of suppression of pituitary and gonadal function after acute or prolonged administration of a luteinizing hormone-releasing hormone antagonist in normal men. J Clin Endocrinol Metab. 68:446-454.

13. Pavlou SN, Brewer K, Farley MG, et al. 1991 Combined administration of a gonadotropin-releasing hormone antagonist and testosterone in men induces reversible azoospermia without loss of libido. J Clin Endocrinol Metab. 73:1360-1369.

14. Jockenhovel F, Bhasin S, Steiner BS, Rivier JE, Vale WW, Swerdloff RS. 1988 Hormonal effects of single gonadotropin-releasing hormone antagonist doses in men. J Clin Endocrinol Metab. 66:1065-1070.

15. Salameh W, Bhasin S, Steiner B, McAdams LA, Peterson M, Swerdloff $\mathbf{R}$. 1991 Marked suppression of gonadotropins and testosterone by an antagonist analog of gonadotropin-releasing hormone in men. Fertil Steril. 55:156-164.

16. Tom L, Bhasin S, Salameh W, et al. 1992 Induction of azoospermia in normal men with combined Nal-Glu gonadotropin-releasing hormone antagonist and testosterone enanthate. J Clin Endocrinol Metab. 75:476-483.

17. Bremner WJ, Bagatell CJ, Steiner RA. 1991 Gonadotropin-releasing hormone antagonist plus testosterone: a potential male contraceptive. J Clin Endocrinol Metab. 73:465-469.

18. Bagatell CJ, McLachlan RI, de Kretser DM, et al. 1989 A comparison of the suppressive effects of testosterone and a potent new gonadotropin-releasing hormone antagonist on gonadotropin and inhibin levels in normal men. J Clin Endocrinol Metab. 69:43-48.

19. Bagatell CJ, Matsumoto AM, Christensen RB, Rivier JE, Bremner WJ. 1993 Comparison of a gonadotropin releasing-hormone antagonist plus testosterone (T) vs. T alone as potential male contraceptive regimens. J Clin Endocrinol Metab. 77:427-432.

20. Bagatell CJ, Rivier JE, Bremner WJ. 1995 Dose effects of the gonadotropinreleasing hormone antagonist, Nal-Glu, combined with testosterone enanthate on gonadotropin levels in normal men. Fertil Steril. 64:139-145.

21. Behre HM, Klein B, Steinmeyer E, McGregor GP, Voigt K, Nieschlag E. 1992 Effective suppression of luteinizing hormone and testosterone by single doses of the new gonadotropin-releasing hormone antagonist cetrorelix (SB-75) in normal men. J Clin Endocrinol Metab. 75:393-398.

22. Behre HM, Bockers A, Schlingheider A, Nieschlag E. 1994 Sustained suppression of serum LH, FSH and testosterone and increase of high-density lipoprotein cholesterol by daily injections of the $\mathrm{GnRH}$ antagonist cetrorelix over 8 days in normal men. Clin Endocrinol (Oxf). 40:241-248.

23. Behre HM, Kliesch S, Puhse G, Reissmann T, Nieschlag E. 1997 High loading and low maintenance doses of a gonadotropin-releasing hormone antagonist effectively suppress serum luteinizing hormone, follicle-stimulating hormone, and testosterone in normal men. J Clin Endocrinol Metab. 82:1403-1408. 
24. Bebb RA, Anawalt BD, Christiansen RB, Paulsen CA, Bremner WJ, Matsumoto AM. 1996 Combined administration of levonorgestrel and testosterone induces more rapid and effective suppression of spermatogenesis than testosterone alone: a promising male contraceptive approach. J Clin Endocrinol Metab. 81:757-62.

25. World Health Organization. 1992 Laboratory manual for the examination of human semen and sperm-cervical mucus interaction. Cambridge: Cambridge University Press.

26. Salahian B, Wang C, Alexander G, et al.1995 Pharmacokinetic, bioefficacy and safety of sublingual testosterone cyclodextrin in hypogonadal men: comparison to testosterone enanthate. J Clin Endocrinol Metab. 80:3567-3575.

27. Wang C, Alexander G, Berman N, et al. 1996 Testosterone replacement therapy improves mood in hypogonadal men-a clinical research center study. J Clin Endocrinol Metab. 81:3578-3583.

28. Wang C, Berman NG, Veldhuis JD, et al. 1998 Graded testosterone infusions distinguish gonadotropin negative-feedback responsiveness in Asian and White men-A clinical research center study. J Clin Endocrinol Metab. 83:870-876.

29. Meriggiola MC, Bremner W. 1997 Progestin-androgen combination regimens for male contraception. J Androl. 18:240-244.

30. Sinha-Hikim A, Wang C, Leung A, Swerdloff RS. 1995 Involvement of apoptosis in the induction of germ cell degeneration in adult rats after gonadotropin-releasing hormone antagonist treatment. Endocrinology. 136: $2770-2775$.
31. Weinbauer GF, Limbergner A, Behre HM, Nieschlag E. 1994 Can testosterone alone maintain the gonadotrophin-releasing hormone antagonist-induced suppression of spermatogenesis in the non-human primate? J Endocrinol. 142:485-495.

32. Behre HM, Kliesch S, Lemcke B Nieschlag E. 1995 Suppression of spermatogenesis to azoospermia by combined administration of GnRH antagonist and 19-Nortestosterone cannot be maintained by 19-nortestosterone alone in normal men. Proc. 77th Annual Meeting of The Endocrine Society, Washington DC, 1995, Abstract OR 24-6.

33. Behre HM, Nieschlag E. 1992 Testosterone buciclate (20-Aet-1) in hypogonadal men: pharmacokinetics and pharmacodynamics of the new long-acting androgen ester. J Clin Endocrinol Metab. 75:1104-1210.

34. Behre HM, Baus S, Kliesch S, Keck C, Simoni M, Nieschlag N. 1995 Potential of testosterone buciclate for male contraception: endocrine differences between responders and non-responders. J Clin Endocrinol Metab. 80:2394-2403.

35. Bhasin S, Swerdloff RS, Steiner B, et al. 1992 A biodegradable testosterone microcapsule formulation provides uniform eugonadal levels of testosterone for 10 to 11 weeks in hypogonadal men. J Clin Endocrinol Metabol. 74:75-83.

36. Handelsman DJ, Conway AJ, Boylan LM. 1992 Suppression of human spermatogenesis by testosterone implants. J Clin Endocrinol Metabol. 75:13261332. 